\title{
Efeito sazonal sobre os ácidos graxos e colesterol do polvo Octopus vulgaris Cuvier 1797
}

\author{
Seasonal effects on fatty acids and cholesterol contents in Octopus vulgaris Cuvier 1797
}

\author{
Margarida Maria Monteiro VASCONCELOS ${ }^{1 \star}$, Jorge Fernando Fuentes ZAPATA²
}

\begin{abstract}
Resumo
Foi realizado um estudo sobre o perfil de ácidos graxos e colesterol na manta de polvo comum, Octopus vulgaris, capturado na praia de Camocim - CE, no decorrer dos meses de abril a outubro em coletas bimensais. Apesar do ácido oleico (C18: 1n9) apresentar comportamento uniforme ao longo do tempo de coleta, a maioria dos demais ácidos graxos foi afetada ( $\mathrm{p}=1 \%)$ pela época de coleta. Os níveis dos ácidos araquidônico (C20:4n6), oleico (C18:1n9), esteárico (C18:0) e linoleico (C18:2n6) foram superiores àqueles reportados na literatura. O somatório de ácidos graxos poli-insaturados e monoinsaturados revelou que o óleo de polvo apresenta um teor significativo de ácidos graxos insaturados. Foi observado um aumento gradativo de colesterol ao longo do tempo estudado e um comportamento inverso para a relação de ácidos graxos n3/n6.
\end{abstract}

Palavras-chave: ácidos graxos poli-insaturados; colesterol; sazonalidade; manta de polvo.

\begin{abstract}
The aim of this study was to investigate the fatty acids and cholesterol profile in the mantle of common octopus, Octopus vulgaris, collected twice a month in in coastal waters of Camocim/CE beach over the period from April to October. Although the Oleic acid (C18:n9) did not show significant changes over the months, the majority of fatty acids varied during this period of time. The Arachidonic (C20:4n6), oleic (C18:n9), stearic (C18:0), and linoleic (C18:2n6) acids were found in higher levels than those reported in the literature. Polyunsaturated and unsaturated fatty acids accounted for most of the octopus fatty acids. During the time of analysis, it was observed a gradual increase in the cholesterol and the fatty acids $\mathrm{n} 3 / \mathrm{n} 6$ ratio presented the opposite result, i.e., a gradual decrease.
\end{abstract}

Keywords: polyunsaturated fatty acids; cholesterol; seasonal; mantle of octopus.

\section{Introdução}

Os ácidos graxos essenciais são componentes estruturais importantes de todas as membranas, tanto revestindo uma célula quanto no seu interior. A composição lipídica da dieta e o adequado consumo de ácidos graxos do tipo cis estão diretamente relacionados à composição da membrana celular, uma vez que esses ácidos atuam como elementos de comunicação entre as células, sendo precursores de certas prostaglandinas, além de controlarem o nível de colesterol e favorecerem a permeabilidade da pele. Deste modo, os ácidos graxos essenciais insaturados na forma cis têm efeito protetor quando disponíveis em concentrações normais no organismo (GURR, 1992; WAHLE; JAMES, 1993).

Para Arts, Ackman e Holub (2001), os ácidos graxos estão ligados à chave dos processos fisiológicos e bioquímicos e são, dessa forma, parte integral do funcionamento próprio dos ecossistemas. Os organismos aquáticos têm sido e continuam a ser nossa fonte primária prontamente aproveitável e existe uma crescente evidência de que os ácidos graxos essenciais sejam uma potente base em nosso processo evolutivo, estando, desta forma, ligados diretamente com nossa compleição orgânica e indiretamente com aquilo que nos foi repassado geneticamente por nossos ancestrais.
Dentre as espécies marinhas de interesse biológico e comercial, destacam-se alguns membros da classe dos cefalópodes que, conforme Domínguez, Cortés e Várquez (2004), constituem espécies predadoras ativas, possuindo um papel determinante nas estruturas tróficas dos oceanos, sendo também um importante recurso pesqueiro, consumido regularmente em diversas regiões do planeta. Quanto à estrutura físico-química, a parte comestível desses indivíduos compõe-se basicamente de água (80\%), 16,6\% de proteína, cerca de $1 \%$ de carboidratos e menos de $2 \%$ de lipídios (IWASAKI; HARADA, 1985; VLIEG, 1984).

$\mathrm{Na}$ atualidade, a importância dos recursos marinhos, tanto para uso alimentar como para farmacologia, tem levado várias pesquisas a abordar o comportamento biológico e bioquímico dessas espécies. Aquelas direcionadas ao estudo do cultivo de espécies marinhas destacam a importância da facilidade adaptativa às condições em cativeiro e as altas taxas de crescimento e de reprodução, rusticidade alimentar e alto preço no mercado formal, sendo indicado na literatura o cultivo de Octopus vulgaris por apresentar tais condições básicas (RODRÍGUEZ et al., 2006; PIRES; SEIXAS; BARBOSA, 2004). Para Navarro e Villanueva (2003), o ciclo de vida do

Recebido para publicação em 1/4/2008

Aceito para publicação em 4/1/2009 (003333)

Departamento de Tecnologia de Alimentos, Faculdade de Tecnologia do Instituto Centro de Ensino Tecnológico - FATEC, CEP 62040-730, Sobral - CE, Brasil, E-mail: guidamv@hotmail.com

2 Departamento de Tecnologia de Alimentos, Universidade Federal do Ceará - UFC, Fortaleza - CE, Brasil

${ }^{*}$ A quem a correspondência deve ser enviada 
polvo é considerado curto, variando entre 12 e 18 meses, além do que, sob condições de cativeiro, esse molusco pode apresentar altas taxas de conversão alimentar, de 15 a 43\%, dependendo da temperatura e da dieta ofertada. Um outro direcionamento focado nas características bioquímicas dessa espécie persegue a qualificação e quantificação dos lipídios presentes, mais precisamente a natureza de seus ácidos graxos. Todos os cefalópodes adultos possuem grandes concentrações de ácidos graxos de cadeia longa (AGPI), entre eles o ácido docosahexaenoico (DHA), o ácido eicosapentaenoico (EPA) e o ácido araquidônico (AA). O DHA tem um papel multifuncional em vários processos adaptativos que ocorrem nas membranas, o EPA e o AA são dois dos mais importantes percussores do ácido eicosanoico, que está implicado em múltiplas funções na bioquímica celular (DOMÍNGUEZ; CORTÉS; VÁZQUEZ, 2004; NASH; EATON; CREWE, 1978).

A composição dos esteróis em moluscos varia de classe para classe. Conforme Kanazawa (2001), em gastrópodes e cefalópodes, observa-se, primariamente, a presença de colesterol $\left(\mathrm{C}_{27}\right)$, contendo pequenas amostras de esteróis do tipo $\mathrm{C}_{28}$ e $\mathrm{C}_{29}$, reflexo da incorporação através da dieta dos fitosteróis algais. De acordo com esse autor, esteróis isolados de moluscos marinhos têm apresentado capacidade de exercer efeito hipocolesterolêmico, como é o caso do 7-colestenol (beta) e do 24-metilenocolesterol que, em ensaios com ratos, apresentaram uma diminuição significativa no nível de colesterol tanto no soro quanto no fígado dessas cobaias.

A presente pesquisa teve por objetivo analisar o comportamento sazonal dos ácidos graxos e do colesterol presentes na manta de polvo comum, Octopus vulgaris, capturado na praia de Camocim - CE, durante um período de seis meses.

\section{Material e métodos}

A coleta de polvo, Octopus vulgaris, foi realizada nos meses de abril, julho e novembro, na praia de Camocim - CE. Foram adquiridos exemplares de capturas artesanais, eviscerados, de aproximadamente $500 \mathrm{~g}$ de peso da espécie em questão, sendo o material acondicionado em gelo. As amostras do tecido foram coletadas da manta dos cefalópodes e moídas em moedor de carne provido de disco com furos de $4 \mathrm{~mm}$ de diâmetro. $\mathrm{O}$ músculo moído foi acondicionado em freezer a $-18{ }^{\circ} \mathrm{C}$ até posterior uso.

Os lipídios totais foram extraídos conforme Folch, Less e Sloane-Stanley (1957), usando-se clorofórmio e metanol na proporção de 2:1 e uma solução salina de $\mathrm{CaCl}_{2}$ a $0,05 \%$ para a separação uniforme das fases. A preparação da gordura extraída para análise cromatográfica de ácidos graxos e colesterol foi realizada conforme metodologia descrita por Vasconcelos, Craveiro e Zapata (2004), retirando-se uma alíquota de $150 \mathrm{mg}$ do óleo extraído para a realização do processo de metilação, usando-se, para tanto, $5 \mathrm{~mL}$ de uma solução de metóxido de sódio ( $1 \mathrm{~g}$ de sódio metálico para $100 \mathrm{~mL}$ de álcool metílico) previamente preparada. O colesterol e os ésteres metílicos resultantes foram então extraídos com $100 \mathrm{~mL}$ de hexano, sendo $3 \mathrm{~mL}$ desse extrato transferidos para recipientes de 3,5 mL. Em seguida, $3 \mu \mathrm{L}$ dessa solução foram injetados num cromatógrafo de gás Hewlett 5890 Packard série II, com detector seletivo de massas.

Para a identificação e quantificação do colesterol, seguiu-se o método de Alencar, Craveiro e Matos (1984), usando-se um padrão externo de colesterol $\left(500 \mathrm{mg}\right.$ de colesterol.100 $\mathrm{mL}^{-1}$ de hexano), preparado de acordo com Vasconcelos, Craveiro e Zapata (2004). Os ácidos graxos e o colesterol foram separados em coluna do tipo metil-fenil-silicone de $25 \mathrm{~m}$ e $0,32 \mathrm{~mm}$ de diâmetro, usando-se temperaturas programadas da coluna de 50 para $180^{\circ} \mathrm{C}$ à razão de $4{ }^{\circ} \mathrm{C} /$ minuto e de 180 para $280^{\circ} \mathrm{C}$ de $20^{\circ} \mathrm{C} /$ minuto. A identificação e quantificação percentual dos ácidos graxos foram realizadas conforme os critérios descritos por Alencar, Craveiro e Matos (1984), para análise de voláteis, utilizando as leituras do índice de Kovats, combinadas com a massa espectral obtida através dos cromatogramas. O ensaio foi realizado em duplicata com uma repetição. Os cálculos dos somatórios e quocientes dos AGPI, AGS e dos ácidos n 3 e n6 foram realizados com base nos valores percentuais médios obtidos desses ácidos graxos.

Os resultados obtidos dos níveis de gordura total e do perfil de ácidos graxos e colesterol foram tratados estatisticamente pela análise de variância (ANOVA), e as médias comparadas pelo Teste de Tukey usando-se o programa estatístico Origin.

\section{Resultados e discussão}

Os resultados médios de gordura total extraída na manta de polvo comum, Octopus vulgaris, no decorrer dos seis meses de coletas bimensais (Tabela 1), indicaram baixos níveis desse componente químico variando de 0,22 a $0,12 \%$. Navarro e Villanueva (2003), analisando o teor lipídico em Octopus vulgaris em função de sua fase de desenvolvimento, reportaram valores que, em geral, foram decrescentes em função do ganho de peso, com variações entre 6,6 e 12\% por mg de peso seco. Para Miliou et al. (2006), além do peso corporal, a composição química em octopus varia com o aumento da temperatura. Rosa, Pereira e Nunes (2005), estudando a variação bioquímica em 14 cefalópodes na costa portuguesa, identificaram que, no tocante a teor lipídico, a lula gigante apresenta altos valores nas gônadas e glândula digestiva e baixas leituras no músculo. Sinanoglou e Miniadis-Meimaroglou (1998) apontaram variações de 2,0 a 1,4\% no teor de lipídios totais no manto de cefalópodes do Mediterrâneo. Sieiro et al. (2005) identificaram teores lipídicos na manta de polvo comum, de 14,99\% por peso úmido. Os resultados desta pesquisa revelaram valores abaixo daqueles indicados pela literatura, porém deve-se levar em consideração que os organismos marinhos da zona tropical apresentam altas taxas metabólicas em função das altas temperaturas (DALY; PECK, 2000), desta forma, conforme Rosa, Costa e Nunes (2004), as reservas lipídicas são provavelmente armazenadas nas glândulas digestivas e não na manta (ROSA; COSTA; NUNES, 2004).

No decorrer dos seis meses de experimento (abril a outubro), foram verificadas variações tanto no tipo como na quantidade de ácidos graxos presentes nas amostras de óleo de manta de polvo, Octopus vulgaris, variações essas discriminadas 
Tabela 1. Ácidos graxos e colesterol (\%) encontrados no óleo de manta de polvo, Octopus vulgaris, proveniente de Camocim - CE, no período de abril a outubro.

\begin{tabular}{|c|c|c|c|}
\hline Componentes lipídicos em óleos de polvo & Abril & Junho & Outubro \\
\hline C16:0 & $16,15^{\mathrm{a}} \pm 1,08$ & $13,11^{\mathrm{b}} \pm 0,69$ & $11,23^{b} \pm 0,86$ \\
\hline $\mathrm{C} 180$ & $13,53^{\mathrm{a}} \pm 1,44$ & $16,36^{\mathrm{b}} \pm 2,08$ & $11,76^{\mathrm{c}} \pm 0,55$ \\
\hline C20 4n6 & $16,46^{\mathrm{a}} \pm 2,11$ & $17,59^{\mathrm{b}} \pm 0,24$ & $15,73^{\mathrm{a}} \pm 1,59$ \\
\hline C18:2n6 & $3,09^{\mathrm{a}} \pm 0,14$ & $5,29^{\mathrm{b}} \pm 0,01$ & $5,22^{\mathrm{b}} \pm 0,08$ \\
\hline $\mathrm{C} 18: \ln 8$ & $6,39^{a} \pm 0,42$ & $1,34^{\mathrm{b}} \pm 0,01$ & $3,74^{\mathrm{c}} \pm 0,14$ \\
\hline $\mathrm{C} 18: 3 \mathrm{n} 3$ & - & $5,20^{\mathrm{b}} \pm 0,55$ & $1,39^{c} \pm 0,08$ \\
\hline $\mathrm{C} 16: 3 \mathrm{n} 3$ & $2,82^{\mathrm{a}} \pm 0,04$ & $1,47^{\mathrm{b}} \pm 0,09$ & - \\
\hline $\mathrm{C} 16: \ln 6$ & $2,42^{\mathrm{a}} \pm 0,12$ & $0,45^{\mathrm{b}} \pm 0,01$ & - \\
\hline $\mathrm{C} 17: 0$ & - & $1,29^{\mathrm{b}} \pm 0,29$ & $1,56^{c} \pm 0,01$ \\
\hline C18:3n6 & $2,29 \pm 0,07$ & - & - \\
\hline$\Sigma$ Saturados & 29,68 & 30,76 & 25,13 \\
\hline$\Sigma$ Monoinsaturados & 14,99 & 7,50 & 10,91 \\
\hline$\Sigma$ Poli-insaturados & 27,54 & 31,43 & 23,58 \\
\hline Relação AGPI/ AGS & 0,93 & 1,02 & 0,94 \\
\hline Relação n3/n6 & 0,11 & 0,28 & 0,06 \\
\hline
\end{tabular}

Letras minúsculas diferentes posicionadas em uma mesma linha indicam diferenças significativas ao nível de $1 \%$ de probabilidade; $^{*}$ inclui na sua maioria ciclopropano.

na Tabela 1. Excetuando-se o ácido oleico (C18:1n9), que apresentou comportamento uniforme ao longo do tempo de pesquisa (3,70\% em abril; 3,65\% em julho; e 3,88\% em outubro), os demais ácidos graxos demonstraram forte tendência sazonal ( $\mathrm{p}<0,01 \%)$, inclusive com alguns registrando presença esporádica ao longo do tempo pesquisado, como foi o caso dos ácidos graxos C18:3n3 e C17:0 (julho e outubro); C16:3n3 e C16:1n6 (abril e julho); C18:3n6 (abril); e C14:0 (outubro). Ressalta-se que o nível quantitativo desses ácidos graxos esporádicos também não foi expressivo, apresentando leituras máxima e mínima no mês de julho de 5,20\% (C18:3n3) e 0,45\% ( C16:1n6), respectivamente. Moreno et al. (1998), estudando os ácidos graxos presentes em variados tecidos de Illex argentinus proveniente do Atlântico Sul, verificaram altos percentuais de ácidos graxos dos tipos C16:0; C18:0; C18:1n9; C20:1; C22:1; C20:5n3 e C22:6 n3.

Conforme pesquisa de Miliou et al. (2006), a temperatura influencia a proporção de alguns ácidos graxos, sendo aumentada $(\mathrm{p}<0,01)$ em relação ao peso corporal especificamente para C18:1n9, C18:1n7, C18:2n6, C20:4n6, C22:4n6 e C22:5n6, enquanto os poli-insaturados totais e $\mathrm{n} 3$ altamente insaturados (AGAI) decrescem em polvos maiores tanto a baixas como a altas temperaturas $\left(15 \mathrm{e} 25^{\circ} \mathrm{C}\right.$, respectivamente), no entanto a $25^{\circ} \mathrm{C}, \mathrm{o}$ total de saturados, monoinsaturados e n6 AGAI aumenta.

A presença significativa de ácido araquidônico (C20:4n6), entre 15,73 e $17,59 \%$, durante o período pesquisado confirmou que $O$. vulgaris é uma excelente fonte desse ácido, observação essa também descrita na literatura, porém com valores bem menores que os reportados na presente pesquisa: 2,4 a 9,6\%
(MILIOU et al., 2006); 2,8 a 5,6\% (NAVARRO; VILLANUEVA, 2003), e 3,8 a 6,9\% (DOMÍNGUEZ; CORTÉS; VÁZQUEZ, 2004).

Foram observados altos níveis de ácido palmítico (C16:0), com valores variando decrescentemente ao longo do tempo (16,15 a 11,23\%); e esteárico (C 18:0), o qual apresentou um teor expressivo no mês de julho (16,36\%). Zlatanos et al. (2006), avaliando a composição química de cefalópodes do Mediterrâneo, inclusive octópodes, indicaram que os ácidos graxos mais abundantes eram os ácidos docosahexaenoico, o palmítico e o eicosapentaenoico. Os níveis de C16:0, nesta pesquisa, estão abaixo daqueles revelados por Domínguez, Cortés e Várquez (2004), 16,5 a 21,6\%, em juvenis de polvo e dos reportados por Sinanoglou e Miniadis-Meimaroglou (1998), 17,27 a 26,66\%, em cefalópodes do Mediterrâneo. Entretanto os níveis de C18:0 (16,36 a 11,76\%), C18:1n9 (3,88 a $3,65 \%)$ e C18:2n6 (5,29 a 3,09\%), revelados nesta pesquisa, indicam valores acima daqueles estipulados por Domínguez, Cortés e Várquez (2004) de 7,9 a 10,6\%; 2,4 a 1,6\%; e 2,0 a 0,4\%, respectivamente. Rosa, Pereira e Nunes (2005), pesquisando compostos bioquímicos em 14 espécies de cefalópodes na costa de Portugal, evidenciaram que a maioria dos ácidos graxos presentes nesses indivíduos eram do saturado C 16:0; dos monoinsaturados como C18:1 e C20:1; e dos poli-insaturados como C20:4n6, C20:5n3 e C22:6n3. Sinanoglou e MiniadisMeimaroglou (1998), avaliando os níveis de lipídios em três espécies de cefalópodes do Mediterrâneo, encontraram os valores mais expressivos de C22:6n3 (24,71 a $35,70 \%)$ e de C20:5n3 (15,65 a 17,59\%). 
O somatório de ácidos graxos poli-insaturados indicados nesta pesquisa (27,54\% em abril; $31,43 \%$ em julho; e $23,58 \%$ em outubro) apresentou aumento do mês de abril para o mês de julho (27,54 e $31,43 \%$, respectivamente), porém este índice encontra-se abaixo daquele indicado por Miliou et al. (2006). Num estudo comparativo entre a composição de ácidos graxos em $O$. vulgaris em função da temperatura e peso corporal, esses autores encontraram altos conteúdos de ácidos graxos poli-insaturados (51,32 a 57,62\% do total de ácidos graxos), especialmente dos n 3 altamente insaturados (38,01 a 52,73\% do total de ácidos graxos). Navarro e Villanueva (2003) apontaram valores entre 41,7 e $54,8 \%$ no somatório de AGPI em juvenis de polvo comum. Moreno et al. (1998), estudando a variação bioquímica de Illex argentinus entre os meses de fevereiro a junho, reportaram valores para os ácidos graxos saturados de $35,9,13,10 \%$ para os monoinsaturados e $51,00 \%$ para os poliinsaturados, entretanto, nessa pesquisa os autores não observaram variações desses constituintes ao longo do tempo estudado.

Foram observadas variações, ao longo do tempo de pesquisa, nos valores dos somatórios de AGPI, AGS, monoinsaturados e da relação entre n $3 / \mathrm{n} 6$, sendo reportadas leituras mais significativas no mês de julho para AGS $(30,76 \%)$ e AGPI $(31,43 \%)$ e no mês de abril para os monoinsaturados (14,99\%). Em decorrência destas variações, a relação $\mathrm{n} 3 / \mathrm{n} 6$ foi mais pronunciada no mês de julho $(0,28 \%)$. O somatório de AGS foi ligeiramente maior do que aquele encontrado para AGPI e este, maior do que para os monoinsaturados, porém, em relação aos valores gerais de insaturados (mono e poli-insaturados), foi observado que o óleo pesquisado possui maior nível desses ácidos graxos.

Sieiro, Aubourg e Rocha (2006), estudando os níveis lipídicos de O. vulgaris em quatro tecidos distintos (braços, manto, ovário e glândulas digestivas), observaram um alto teor de AGS e AGPI no ovário e tecido muscular, respectivamente, sendo apresentadas variações sazonais tanto nos níveis de AGS quanto de AGPI. Para Navarro e Villanueva (2003), o somatório de AGPI em juvenis de polvo comum mostra uma maior porcentagem de poli-insaturados $(41,7$ a $54,81 \%)$ se comparados às taxas reportadas para saturados (27,1 a 35,4\%) e monoinsaturados (12,1 a 8,6\%). Miliou et al., (2006) observaram taxas de n3/n6 maiores que 3,0 em relação à temperatura do mar e peso corporal em polvo, taxas essas semelhantes àquelas indicadas por Navarro e Villanueva (2003) em juvenis de polvo comum (3,4 a 7,6\%). Os valores encontrados na presente pesquisa situam-se abaixo daqueles reportados pelos citados autores, em decorrência, provavelmente, da alta variação encontrada para C18:3n3 durante os meses de análises (não detectável em abril, 5,20\% em julho e 1,39\% em outubro).

A relação AGPI/AGS encontrada para o óleo da manta presente em Octopus vulgaris foi de 0,93 no mês de abril; 1,02 em julho; e 0,94 em outubro. Conforme indica Enser et al. (1998), o Departamento de Saúde da Inglaterra para Alimentos Integrais recomenda que essa relação seja de no mínimo $0,45 \%$ para que o alimento seja considerado indicado para dietas humanas. Desta forma, os valores encontrados nesta pesquisa para óleo de polvo sugerem que o consumo deste alimento é recomendável. Para Navarro e Villanueva (2003), em estudo sobre o perfil de ácidos graxos em larvas cultivadas de O. vulgaris, o perfil de ácidos graxos obtidos através da análise dos fosfoglicerídeos mostraram uma maior porcentagem de AGPI, particularmente n3, do que aquele obtido através dos lipídios totais. Pesquisa realizada por Rosa, Nunes e Sousa Reis (2000), no tocante à sazonalidade do teor lipídico em $O$. vulgaris coletado em Portugal, revelou que as percentagens dos ácidos graxos poli-insaturados tiveram variações sazonais semelhantes no decorrer do tempo pesquisado, sugerindo que essas variações podem estar relacionadas com a oogénese e a espermatogênese do animal.

Foi observada a presença de outros constituintes na fração lipídica do músculo de polvo, em sua maioria ciclopropano, não sendo, entretanto, sugerida variação sazonal durante esse período. Para Mota (2000), o ciclopropano é um alcano ramificado resultante da isomerização do esqueleto hidrocarbônico de alcanos lineares. Conforme Proudfoot, Xian e Djerassi (1985), a presença do anel ciclopropano é um aspecto único dos esteróis marinhos, formado, em sua maioria, a partir de substituições simples, nas quais o anel desse composto aparece como elo entre as cadeias carbônicas. Para Christie e Holman (1966), em análises quantitativas de ciclopropanos a partir de insaturados, a massa spectral dos monociclopropanos é muito similar àquela dos ésteres insaturados que lhe deram origem, sendo talvez essa a razão do aparecimento de valores percentuais de ciclopropanos nos cromatogramas obtidos na presente pesquisa (Figura 1).

Os níveis de colesterol apresentados no decorrer da pesquisa revelaram um aumento gradativo desse esterol ao longo do tempo, sendo observado o maior valor no mês de outubro (30,32\%). Sieiro et al. (2005), estudando o efeito do derramamento de óleo em função da composição bioquímica de $O$. vulgaris, estabeleceram que, em áreas não afetadas por tal problema, o valor dos esteróis no manto foi de $1,77 \mathrm{mg} \cdot \mathrm{g}^{-1}$ de peso seco. Moxica et al., (2004) indicaram variações ao longo do tempo nos esteróis presentes em larvas de polvo $(8,30$ para 17,95\%). Sinanoglou e Miniadis-Meimaroglou (1998) apontaram variações da ordem de 0,6 a $5,4 \%$ para ésteres de esterol em três espécies de cefalópodes do Mediterrâneo, enquanto que, para Domínguez, Cortés e Várquez (2004), o valor definido para ésteres de esteróis foi de 10,93 e de 29,27\% de colesterol em Sepia officinalis. Rosa, Nunes e Sousa Reis (2000), estudando o teor em colesterol nas glândulas digestivas de polvo comum, observaram que o incremento nos níveis desse esterol

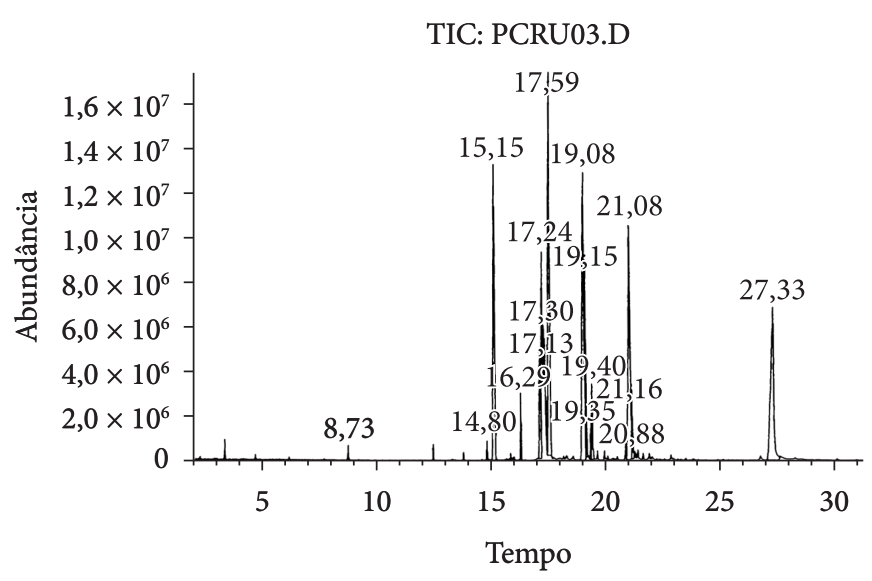

Figura 1. Cromatograma referente às análises de ácidos graxos e colesterol em óleo de polvo, Octopus vulgaris. 
parece estar relacionado com o processo de maturação sexual, uma vez que a produção de hormônios sexuais está relacionada ao metabolismo deste composto.

\section{Conclusões}

O óleo de manta de polvo comum revelou-se como uma excelente fonte de ácido araquidônico além de esteárico, oleico, linoleico e palmítico. O somatório de AGPI e monoinsaturados juntos indicou que o óleo pesquisado possui altos níveis de ácidos graxos insaturados. A taxa de n3/n6 no óleo pesquisado reportou valores abaixo daqueles indicados pela literatura consultada, enquanto que o inverso foi observado para os níveis de colesterol.

Foi verificado, com exceção para o ácido oleico, que os principais ácidos graxos e o colesterol do óleo de manta de polvo, coletados no litoral do Estado do Ceará, variam sazonalmente no período de abril a outubro.

\section{Referências bibliográficas}

ALENCAR, J. W.; CRAVEIRO, A. A.; MATOS, F. A. Kovacs indices as a preselection routine in mass spects library search of volatiles. Journal of Natural Products, v. 47, n. 5, p. 890-892, 1984.

ARTS, M. T.; ACKMAN, R. G.; HOLUB, B. J. Essential fatty acids in aquatic ecosystems: a crucial link between diet and human health and evolution. Canadian Journal of Fisheries and Aquatic Sciences, v. 58, n. 1, p. 122-137, 2001.

CHRISTIE, W. W.; HOLMAN, R. T. Mass spectrometry of lipids. I: Cyclopropane fatty acid esters. Lipids: Biomedical and Life Sciences, v. 1, n. 3, p. 176-182, 1966.

DALY, I.; PECK, L. S. Energy balance and cold adaptation in the octopus Pareledone charcoti. Journal of Experimental Marine Biology and Ecology, v. 245, n. 2, p. 197-214, 2000.

DOMÍNGUEZ, P.; CORTÉS, G.; VÁZQUEZ, C. R. Alimentación y Nutrición de Moluscos Cefalópodos: Avances Recientes y Perspectivas Futuras. In: CRUZ SUÁREZ, L. E. et al., (Eds.). AVANCES EN NUTRICIÓN ACUÍCOLA; MEMORIAS DEL SIMPOSIUM INTERNACIONAL DE NUTRICIÓN ACUÍCOLA, VII; VII, 16-19 Noviembre 2004, Hermosillo, Sonora/ México.

ENSER, M. et al., Fatty acid contend and composition of UK beef and lamb muscle in relation to production system and implications for human nutrition. Meat Science, v. 49, n. 3, p. 329-341, 1998.

FOLCH, J.; LESS, M.; SLOANE - STANLEY, G. H. A simple method for the isolation and purification of total lipids from animal tissue. Journal of Biological Chemistry, v. 226, n. 1, p. 497, 1957.

GURR, M. I. Role of fats in food and nutrition. 2 ed. London: Elsevier Applied Science, 1992. 207 p.

IWASAKI, M.; HARADA, R. Proximate and amino acid composition of the roe and muscle of selected marine species. Journal Food Science, v. 50, n. 6, p. 110 - 113, 1985.

KANAZAWA, A. Sterols in marine invertebrates: Review Article. Fisheries Science, v. 67, n. 6, p. 997-1007, 2001.

MILIOU, H. et al. Fatty acids composition of the common Octopus vulgaris, in relation to rearing temperature and body weight. Aquaculture, v. 256, n. 1-4, p. 311-322, 2006.

MORENO, J. E. A. de. et al. Variations in the biochemical composition of the squid Illex argentinus from the South Atlantic Ocean. Comparative Biochemistry and Physiology, Part B, v. 119, n. 4, p. 631-637, 1998.
MOTA, C. J. A. Íons carbônio. Química Nova, v. 23, n. 3, p. 338-345, 2000.

MOXICA, C. et al. Cultivo intensivo de paralarvas de pulpo, Octopus vulgaris Cuvier, 1797, en tanques de $9 \mathrm{~m}^{3}$. Boletín Instituto Español de Oceanografía, v. 18, n. 1-4, p. 31-36, 2002.

NASH, D. M.; EATON, C. A.; CREWE, N. F. Lipid classes and fatty acid composition of squid (Illex ilecebrosus). Technical Report of the Fisheries and Marine Service of Canada, n. 833, p. 22.1 - 22.3, 1978.

NAVARRO, J. C.; VILLANUEVA, R. The fatty acid composition of Octopus vulgaris paralarvae reared with live and inert food: deviation from their natural fatty acid profile. Aquaculture, v. 219, n. 1-4, p. 613-631, 2003.

PIRES, P. V.; SEIXAS, P.; BARBOSA, A. Aquaculture potential of the common octopus (Octopus vulgaris Cuvier, 1797): a review. Aquaculture, v. 238, n. 1-4, p. 221-238, 2004.

PROUDFOOT, J. R.; XIAN, L.; DJERASSI, C. Minor and trace sterols from marine invertebrates. $50^{1}$. Stereostructure and synthesis of nicasterol, a novel cyclopropane-containing sponge sterol. Journal of Organic Chemistry, v. 50, n. 12, p. 2026-2030, 1985.

RODRÍGUEZ, C. et al. Common octopus (Octopus vulgaris Cuvier, 1797) juvenile ongrowing in floating cages. Aquaculture, v. 254, n. 1- 4, p. 293-300, 2006

ROSA; R. A.; NUNES, M. L.; SOUSA REIS, C. Variações sazonais da composição bioquímica do polvo-comum, Octopus vulgaris, em três zonas da costa portuguesa. Lisboa (Portugal): Instituto de Investigação das Pescas e do Mar/IPIMAR, 2000. 20 p. (Relatórios Científicos e Técnicos n. 61)

ROSA, R.; COSTA, P. R.; NUNES, M. L. Effect of sexual maturation on the tissue biochemical composition of Octopus vulgaris and O. defilippi (Mollusca: Cephalopoda). Marine Biology, v. 145, n. 3, p. 563-574, 2004.

ROSA, R.; PEREIRA, J.; NUNES, M. L. Biochemical composition of cephalopods with different life strategies, with special reference to a giant squid, Architeuthis sp. MarineBiology, v. 146, n. 4, p. 739-751, 2005.

SIEIRO, M. P. et al. Effect of Prestige oil spill on the lipid composition of common octopus (Octopus vulgaris) in Galician coast. In: VERTIMAR/ SYMPOSIUM ON MARINE ACCIDENTAL OIL SPILL, 2005. Disponível em: <http://otvm.uvigo.es/vertimar2005. poster/html.>. Acesso em: 16 out. 2008.

SIEIRO, M. P.; AUBOURG, S. P.; ROCHA, F. Seasonal study of the lipid composition in different tissues of the common octopus (Octopus vulgaris). European Journal of Lipid Science and Technology, v. 108, n. 6, p. 479-487, 2006.

SINANOGLOU, V. J.; MINIADIS-MEIMAROGLOU, S. Fatty acid of neutral and polar lipids of (edible) Mediterranean cephalopods. Food Research International, v. 31, n. 6-7, p. 467-473, 1998.

VASCONCELOS, M. M. M.; CRAVEIRO, A. A.; ZAPATA, J. F. F. Efeito da sazonalidade sobre o colesterol presente em pescado marinho consumido em Fortaleza-CE. Essentia, v. 6, n. 1, p. 45-58, 2004.

VLIEG, P. Proximate composition of New Zealand squid species. New Zealand Journal of Science, v. 27, n. 2, p. 145-150, 1984.

WAHLE, K. W. T; JAMES, W. P.T. Isomeric fatty acids and human health. European Journal Clinical Nutritional, v. 47, n. 12, p. 828-839, 1993.

ZLATANOS, S. et al. Proximate composition, fatty acid analysis and protein digestibility - corrected amino acid score of three Mediterranean cephalopods. Molecular Nutrition \& Food Research, v. 50, n. 10, p. 967-970, 2006. 